\title{
Prosocial Behavior and Moral Reasoning in Italian Adolescents and Young Adults
}

\author{
Maria Elvira De Caroli*, Rossella Falanga, Elisabetta Sagone \\ Department of Educational Sciences, University of Catania, Catania, Italy \\ *Corresponding author: m.decaroli@unict.it
}

Received June 19, 2014; Revised June 29, 2014; Accepted July 04, 2014

\begin{abstract}
This study analyzed the relationships between the inclination to help the others and prosocial moral reasoning (PMR) in a sample of 548 Italian adolescents and young adults. We used the Italian version of Prosocial Tendencies Measure to evaluate the tendencies to adopt prosocial behaviors in different conditions (public, anonymous, and helping behavior in emotionally critical and dire situations) and the two Italian versions of Prosocial Reasoning Objective Measure (respectively for adolescents and adults) in order to assess the general level (composite PMR) and the five typologies of PMR (hedonistic, needs oriented, approval oriented, stereotypical, and internalized prosocial moral reasoning). Results showed that girls scored higher than boys in helping behaviors in emotionally critical and dire situations, while boys scored higher than girls in public behaviors; furthermore, young adults expressed higher levels than adolescents in anonymous behaviors while adolescents scored higher than young adults in public behaviors. In relation to prosocial moral reasoning, girls expressed higher scores than boys in composite PMR and, specifically, in internalized and hedonistic PMR, while boys showed higher levels than girls in stereotypical, needs oriented, and approval oriented PMR. Moreover, young adults reached higher levels than adolescents in composite PMR, especially in internalized and hedonistic PMR; additionally, adolescents obtained higher levels than young adults in stereotypical, needs oriented, and approval oriented PMR. Significant relationships between prosocial behavior and PMR were found: the inclination to use helping behaviors in emotionally critical and dire situations was related positively to levels of composite PMR, especially to internalized PMR, but negatively to approval oriented PMR; public behaviors were related positively to approval and needs oriented PMR, but negatively to composite PMR and, specifically to internalized PMR. Future research will analyze the effects of these dimensions on other psychological constructs such as moral disengagement and value orientations in educational context.
\end{abstract}

Keywords: prosocial behavior, prosocial moral reasoning, adolescents, young adults

Cite This Article: Maria Elvira De Caroli, Rossella Falanga, and Elisabetta Sagone, "Prosocial Behavior and Moral Reasoning in Italian Adolescents and Young Adults." Research in Psychology and Behavioral Sciences, vol. 2, no. 2 (2014): 48-53. doi: 10.12691/rpbs-2-2-3.

\section{Introduction}

Scientific research reserved a wide attention to prosociality, underlining the importance of the inclination to help other people for human development and the building of social relationships ([1,2,3]). In the present research, two main ways to study prosociality were considered: on one hand, the analysis of prosocial behavior, referred to actions intended to benefit others in specific situations [4] and, on the other hand, the reasoning and motivations behind prosocial behaviors [5].

In relation to prosocial behavior, the framework of this study was constituted by Carlo and Randall's [4] perspective, according to which prosocial behavior is better analyzed as a multidimensional construct, formed by a set of interrelated dimensions rather than as a global construct ([6,7]). Carlo and Randall [4] considered prosocial behavior as the inclination to help the others in various social and psychological conditions and distinguished six typologies:

1. public prosocial behaviors as actions that benefit other people in front of an audience to obtain their approval and respect;

2. anonymous prosocial behaviors in terms of tendency to help others without knowledge of whom helped;

3. dire prosocial behaviors as disposition to help other people under crisis or emergency situations;

4. emotional prosocial behaviors as inclination to benefit the others in situations that contain emotionally evocative cues;

5. compliant prosocial behaviors in terms of actions that help other people in response to a verbal or nonverbal request;

6. altruistic prosocial behaviors as the disposition to voluntarily help in absence of a direct and explicit reward to oneself.

Some studies underlined significant differences in relation to sex and age. In a sample of university students, 
Carlo and Randall [4] pointed out that boys were more likely to report public prosocial tendencies than girls; on the contrary, girls scored higher than boys in the inclination to use altruistic, anonymous, emotional, and compliant prosocial behaviors. Similarly, in a study carried out with early and middle adolescents, Carlo et al. [8] found that a) boys scored higher than girls in public prosocial behavior while girls obtained higher levels than boys in emotional and altruistic prosocial behaviors; b) middle adolescents scored higher than early ones on altruistic and anonymous prosocial behaviors.

More recently, in a research involving early and middle Italian adolescents, De Caroli and Sagone [9] identified the following three-factorial structure of prosocial tendencies: 1) public prosocial behaviors, concerning actions directed to benefit other people in the presence of the others; 2) anonymous prosocial behaviors, defined as inclination to help the others without other people's knowledge; 3) helping behaviors in emotionally critical and dire situations, referred to the inclination to help the others under emotionally evocative, emergency or crisis situations. Also in this study, authors found that boys and early adolescents were more likely to report public prosocial behaviors than girls and middle adolescents.

Tightly connected to prosocial behavior, the second topic of the present research was referred to Eisenberg's model $([10,11])$ in relation to the reasons and motivations that drive individuals to decide to act in a prosocial way. According to Eisenberg et al. [12], it was possible to distinguish a range of prosocial moral reasoning (PMR) linked to socio-cognitive development and articulated in five basic typologies analyzed by means of Prosocial Reasoning Objective Measure (PROM) [13]. This measure allowed to obtain scores both for each of the five PMR and for a composite score, that is a general level of moral reasoning obtained by weighing and summing all the category scores $([14,15,16])$.

The five typologies analyzed the development of prosocial moral reasoning (PMR) from self-centered (hedonistic PMR) and other-centered (needs oriented, approval oriented, and stereotypical PMR) to internally driven (internalized PMR) orientations [16]. In the hedonistic PMR, individuals are driven by selfishness and decide to help others only if they receive personal advantages. In needs oriented $P M R$, people give attention to the others' physical, material, and psychological needs without a genuine sense of empathy and understanding of the others' perspective. In approval oriented PMR, subjects help other people in order to obtain consensus or to be popular. In stereotypical PMR, individuals act in a prosocial way only if this behavior was conventionally considered good. In internalized $P M R$, individuals are motivated to help other people by interior values such as responsibility, equity, desire to improve society, and care toward others.

Individual prosocial moral reasoning is composed by more than one typology of reasoning; however, carrying out several longitudinal studies, Eisenberg et al. ([16-21]) underlined that moral reasoning was linked to age. The authors observed that children between 4 and 6 years were predominantly inclined to use the hedonistic PMR while children between 7 and 8 years were mainly likely to adopt the needs oriented PMR; furthermore, adolescents and young adults were chiefly prone to use approval oriented, stereotypical, and internalized PMR. In addition, several studies $([16,18,20,22])$ displayed that levels of composite score on prosocial moral reasoning tended to increase with age and become stable in young adults.

In relation to sex differences, females obtained higher levels than males on composite score in childhood [19], adolescence ([22,23]), with the exception of a sample of Chinese adolescents [24], and in adulthood ([20,25]). In detail, female adolescents scored higher than boys in internalized and needs oriented PMR, while boys scored higher than girls in approval oriented PMR. Furthermore, male university students scored higher than female ones in approval oriented PMR while female university students scored higher than male ones in internalized PMR [25]. The last result was confirmed in Eisenberg et al.' study [20] that showed similar scores in hedonistic PMR between men and women.

The topics of our research were referred to two closely linked aspects of the same issue; however, few studies investigated the relationships between prosocial behavior and moral reasoning $([4,8,26])$. In the study carried out with college students, Carlo and Randall [4] highlighted positive relationships between public prosocial behavior and hedonistic and approval oriented PMR; between emotional and stereotypical and internalized PMR; compliant and internalized PMR; altruism and stereotypical and internalized PMR. On the contrary, these authors noted negative relationships between public and needs oriented and internalized PMR; emotional and hedonistic PMR; altruism and hedonistic and approval oriented PMR. In a study with university students, Hardy and Carlo [26] noted that prosocial reasoning affected altruistic prosocial tendency. Moreover, in the research carried out with early and middle adolescents, Carlo et al. [8] verified positive relationships between public prosocial behavior and approval oriented PMR, between compliant and needs oriented PMR and negative relationships between compliant and hedonistic PMR.

The paucity of studies on prosocial behavior and moral reasoning and on the relationships between these two topics in Italian context represented the rationale of the present study and differences for sex and age were analyzed.

\section{Methodology}

\subsection{Purposes of Study}

According to empirical evidences, we expected differences for sex and age both in prosocial behavior and prosocial moral reasoning. More specifically, we hypothesized that:

1. girls will score higher than boys in anonymous prosocial behaviors (H1a), helping behaviors in emotionally critical and dire situations (H1b), and composite PMR (H1c) while boys scored higher than girls in public prosocial behaviors (H1d);

2. young adults will score higher than adolescents in anonymous prosocial behaviors (H2a) and in helping behaviors in emotionally critical and dire situations (H2b), and in composite PMR (H2c) while adolescents scored higher than young adults in public prosocial behaviors (H2d). 
The second purpose of this research was to analyze relationships between prosocial behavior and moral reasoning. In detail, we hypothesized that:

1. helping behaviors in emotionally critical and dire situations will be positively related to composite PMR and internalized prosocial reasoning and negatively related to hedonistic, needs oriented, approval oriented, and stereotypical prosocial moral reasoning (H3);

2. public prosocial behaviors will be positively related to hedonistic, needs oriented, approval oriented, and stereotypical prosocial moral reasoning and negatively related to composite PMR and internalized prosocial moral reasoning $(\mathrm{H} 4)$;

3. anonymous prosocial behaviors will be positively related to composite PMR and internalized prosocial reasoning and negatively related to hedonistic, needs oriented, approval oriented, and stereotypical PMR (H5).

\subsection{Participants}

The sample consisted of 548 Italian adolescents and young adults (217 boys and 331 girls), between 14 and 24 years $(M=17.67, \mathrm{sd}=2.29)$, randomly recruited from four Public High Schools in Sicily (Italy) and the degree courses of Psychology at Department of Educational Sciences (University of Catania, Italy). After parental consent for the underage students participation to the research, participants were divided into two groups: adolescents (Group 1: $n=314$ ) between 14 and 18,11 years $(\mathrm{M}=16.15$, sd=1.65) and young adults (Group 2: $n=234)$ between 19 and 24 years $(M=19.71$, sd=1.14).

\subsection{Measures and Procedure}

The Prosocial Tendencies Measure [4] was used to evaluate the tendencies to adopt prosocial behaviors in different conditions. In the Italian version proposed by De Caroli and Sagone [9], the scale was composed by 22 items evaluable on a 5-points Likert scale ranging from 1 (does not describe me at all) to 5 (describes me very well). It was possible to distinguish three main factors: anonymous $(\alpha=.77)$ (e.g. "I think that helping others without them knowing is the best type of situation"), public $(\alpha=.76)$ (e.g. "I can help others best when people are watching me”), and helping behavior in emotionally critical and dire situations $(\alpha=.67)$ (e.g., "I tend to help people who are in real crisis or need”).

The Italian versions, respectively for adolescents and adults, of Prosocial Reasoning Objective Measure [13] were used in order to assess the quality of prosocial moral reasoning. Both versions were structured in 7 stories, each representing a conflict between the protagonist's needs and desires and those of the others. The main character of each story was the same gender as the participant (Example of story for girls: One day Mary was going to a friend's party. On the way, she saw a girl who had fallen down and hurt her leg. The girl asked Mary to go to the girl's house and get her parents so the parents could come and take her to a doctor. But, if Mary runs and gets the girl's parents, Mary would be late to the party and miss the fun and social activities with her friends).

The version for adolescents was composed by 5 items to each story, evaluable in a five points scale (from $1=$ =very much to $5=$ none) to assess the importance attributed to each of five reasons for the main character to help or not the other in need in the story. In detail, items were referable to hedonistic ( $\alpha=.57$ ) (e.g. "It depends how much fun Mary expects the party to be, and what sorts of things are happening at the party"), approval oriented $(\alpha=.83)$ (e.g. "It depends whether Mary's parents and friends will think she did the right or wrong thing"), needs oriented $(\alpha=.62)$ (e.g. "It depends whether the girl really needs help or not"), stereotypical ( $\alpha=.65$ ) (e.g. "It depends if Mary thinks it's the decent thing to do or not”), and internalized typologies of PMR $(\alpha=.60)$ (e.g. "It depends how Mary would feel about herself if she helped or not”).

The version for adults was different from the previous one because each of the stories included two items for hedonistic moral reasoning $(\alpha=.83)$ (e.g., "It depends how much fun Mary expects the party to be, and what sorts of things are happening at the party"), two items for internalized ( $\alpha=.82)$ (e.g., "It depends how Mary would feel about herself if she helped or not"), two items for approval oriented $(\alpha=.90)$ (e.g., "It depends whether Mary's parents and friends will think she did the right or wrong thing”), one item for needs oriented ( $\alpha=.71)$ (e.g., "It depends whether the girl really needs help or not"), and one item for stereotypical PMR $(\alpha=.75)$ (e.g., "It depends if Mary thinks it's the decent thing to do or not”).

As in Carlo and Randall's research [4], the lie items were not used in the present study.

\subsection{Data Analysis}

Statistical analyses were conducted applying t-tests, One Way Anova, and linear correlations, using Statistical Package for Social Sciences (SPSS 20 for Windows 7).

The PMR scores were derived by summing the items across the 7 stories for each of the 5 types of prosocial moral reasoning; then, PMR scores were transformed in proportion PMR scores by dividing each of the scores for the 5 types of moral reasoning by the sum of the PMR scores.

The composite PMR, according to Eisenberg et al. [15], was obtained by multiplying hedonistic score for 1 , needsoriented PMR score for 2, approval oriented PMR and stereotypical PMR for 3, and internalized PMR for 4.

Sex (boys vs. girls) and age (Group 1 vs. Group 2) were considered as independent variables, whereas mean scores obtained on the three factors of prosocial tendencies, the composite PMR, and the five typologies of PMR were considered as dependent variables.

\section{Results}

\subsection{Prosocial Behavior}

Descriptive analyses demonstrated that adolescents and young adults were more inclined to use helping behaviors in emotionally critical and dire situations $(\mathrm{M}=3.63$, $\mathrm{sd}=.54)$ than in anonymous ( $\mathrm{M}=2.61, \mathrm{sd}=.87)$ and public behaviors $(\mathrm{M}=1.99, \mathrm{sd}=.68) \quad\left(\mathrm{F}_{(2,546)}=759,84, \mathrm{p}<.001\right)$. Significant differences were noted in relation to sex and age. In detail, girls displayed higher levels than boys in helping behaviors in emotionally critical and dire situations and boys showed higher levels than girls in public behaviors (see Table 1). 
Table 1. Prosocial tendencies - differences for sex $(N=548)$

\begin{tabular}{|c|c|c|c|c|}
\hline \multirow{2}{*}{ PTM } & Boys & Girls & \multirow{2}{*}{$t$} & \multirow{2}{*}{$p$} \\
\cline { 2 - 3 } & $\mathrm{M}(\mathrm{sd})$ & $\mathrm{M}(\mathrm{sd})$ & & \\
\hline Anonymous & $2.56(.88)$ & $2.63(.87)$ &,- 935 & n.s. \\
\hline Helping & $3.55(.58)$ & $3.69(.50)$ & $-3,05$ & .003 \\
\hline Public & $2.27(.70)$ & $1.81(.61)$ & 8,10 & $<.001$ \\
\hline
\end{tabular}

Moreover, young adults expressed higher levels in anonymous behaviors than adolescents; on the contrary, adolescents scored higher than young adults in public behaviors (see Table 2).

Table 2. Prosocial tendencies - differences for age $(N=548)$

\begin{tabular}{|c|c|c|c|c|}
\hline \multirow{2}{*}{ PTM } & Group1 & Group2 & \multirow{2}{*}{$t$} & \multirow{2}{*}{$p$} \\
\cline { 2 - 3 } & M(sd) & M(sd) & & $<.001$ \\
\hline Anonymous & $2.49(.88)$ & $2.76(.84)$ & -3.57 & n.s. \\
\hline Helping & $3.60(.56)$ & $3.69(.50)$ & -1.85 & $<.001$ \\
\hline Public & $2.18(.71)$ & $1.74(.55)$ & 7.81 & $<$ \\
\hline
\end{tabular}

\subsection{Prosocial Moral Reasoning}

General levels of composite PMR ( $\mathrm{M}=2.70 \mathrm{sd}=.11)$ expressed by adolescents and young adults were on the average in relation to results obtained by Eisenberg and colleagues [16].

Significant differences emerged in relation to considered independent variables. More specifically, girls $(\mathrm{M}=2.72 \mathrm{sd}=.11)$ showed higher levels of composite PMR than boys $(\mathrm{M}=2.67 \mathrm{sd}=.10) \quad\left(t_{(546)}=-5.73, \quad p<.001\right)$. In relation to age, young adults expressed higher levels of composite PMR than adolescents (Group 1=2.67, sd=.09 vs. Group $2=2.74 \mathrm{sd}=.13)\left(t_{(546)}=-7.12, p<.001\right)$.

In reference to the five typologies of PMR, adolescents and young adults were more likely to use internalized PMR ( $M=.28, \mathrm{sd}=.07)$ than hedonistic $(\mathrm{M}=.20, \mathrm{sd}=.05)$, stereotypical $(\mathrm{M}=.19, \mathrm{sd}=.05)$, needs oriented $(\mathrm{M}=.17$, $\mathrm{sd}=.05)$, and approval oriented PMR $(\mathrm{M}=.15, \mathrm{sd}=.04)$.

The analysis of differences for sex pointed out that girls scored higher than boys in internalized and hedonistic PMR; on the contrary, boys obtained higher levels than girls in stereotypical, needs oriented, and approval oriented PMR (see Table 3).

Table 3. Prosocial moral reasoning - differences for sex $(N=548)$

Table 3. Prosocial moral reasoning- differences for sex $\mathbf{( N = 5 4 8 )}$
\begin{tabular}{|c|c|c|c|c|}
\hline \multirow{2}{*}{ PMR } & Boys & Girls & \multirow{2}{*}{$t$} & \multirow{2}{*}{$p$} \\
\cline { 2 - 3 } & $\mathrm{M}(\mathrm{sd})$ & $\mathrm{M}(\mathrm{sd})$ & & \\
\hline Hedonistic & $.19(.04)$ & $.21(.05)$ & $-3,76$ & $<.001$ \\
\hline Approval & $.16(.04)$ & $.14(.04)$ & 5,64 & $<.001$ \\
\hline Needs & $.19(.04)$ & $.16(.05)$ & 7,56 & $<.001$ \\
\hline Stereotypical & $.20(.04)$ & $.18(.05)$ & 4,55 & $<.001$ \\
\hline Internalized & $.25(.06)$ & $.31(.07)$ & $-9,31$ & $<.001$ \\
\hline
\end{tabular}

In reference to age, young adults obtained higher levels than adolescents in internalized and hedonistic PMR; furthermore, adolescents obtained higher levels than young adults in stereotypical, needs oriented, and approval oriented PMR (see Table 4).

Table 4. Prosocial moral reasoning - differences for age $(N=548)$

\begin{tabular}{|c|c|c|c|c|}
\hline \multirow{2}{*}{ PMR } & Group1 & Group2 & \multirow{2}{*}{$t$} & \multirow{2}{*}{$p$} \\
\cline { 2 - 3 } & $\mathrm{M}(\mathrm{sd})$ & $\mathrm{M}(\mathrm{sd})$ & & \\
\hline Hedonistic & $.19(.04)$ & $.23(.05)$ & -11.14 & $<.001$ \\
\hline Approval & $.15(.04)$ & $.14(.04)$ & 4.83 & $<.001$ \\
\hline Needs & $.20(.04)$ & $.14(.04)$ & 17.03 & $<.001$ \\
\hline Stereotypical & $.21(.04)$ & $.16(.04)$ & 16.24 & $<.001$ \\
\hline Internalized & $.25(.05)$ & $.33(.06)$ & -18.19 & $<.001$ \\
\hline
\end{tabular}

\subsection{Correlations}

The analysis of Pearson linear correlations between the three types of prosocial behavior and the PMR (composite and the five typologies of PMR) disclosed significant and positive relationships with differences only for sex.

In detail, both for boys and girls the inclination to use helping behaviors in emotionally critical and dire situations was related positively to the levels of composite PMR (boys: $r=.25$, girls: $r=.28$ ) and, specifically, to internalized PMR (boys: $r=.26$, girls: $r=.17$ ), while negatively to approval oriented PMR (boys: $r=-.33$, girls: $r=-.13)$. It meant that the more the participants were inclined to help the others under emotionally evocative, emergency or crisis situations the more they expressed high levels on prosocial reasoning and, specifically, the more they were driven by their internal values. Moreover, the more the adolescents and young adults were inclined to help the others under emotionally evocative, emergency or crisis situations the less they were oriented to give attention to others' approval and acceptance in deciding what is the adequate behavior.

In addition, both for boys and girls, public behavior was related positively to approval oriented (boys: $r=.34$, girls: $r=.37$ ) and needs oriented PMR (boys: $r=.23$, girls: $r=.25$ ) and negatively to composite PMR (boys: $r=-.27$, girls: $r=-$ .20 ) and, specifically, to internalized PMR (boys: $r=-.40$, girls: $r=-.40)$. In this sense, the more the participants were inclined to carry out behaviors directed to benefit other people in the presence of the others, the more they tended to give attention to others' approval and acceptance and to physical, material, or psychological needs of the other individual by choosing the adequate behavior. On the contrary, the more the participants tended to benefit other people in the presence of the others, the less they scored in composite PMR and tended to use prosocial moral reasoning based on internal values such as responsibility, justice, and equity.

Only for girls, anonymous prosocial behavior was related positively to the levels of composite PMR $(r=.22)$ and, specifically, internalized PMR $(r=.26)$ and negatively to needs oriented ( $r=-.22)$ and stereotypical PMR $(r=-.17)$. It meant that the more the girls tended to help the others without other people's knowledge the more they scored in composite PMR and use prosocial moral reasoning based on internal values and the less they give attention to physical, material, or psychological needs of the other people in deciding the adequate behavior.

Furthermore, the more the girls were inclined to use helping behavior helping behaviors in emotionally critical and dire situations the less they used hedonistic PMR $(r=.21)$; additionally, the more the girls tended to use public behaviors the more they used stereotypical $(r=.22)$ and needs oriented PMR $(r=.22)$ and the less they used hedonistic PMR ( $r=-.17)$.

\section{Discussion and Conclusions}

The results of descriptive analyses showed that adolescents and young adults of our sample were more inclined to help the others under emotionally evocative, emergency or crisis situations than to help other people in the presence of the others or without others' knowledge. Moreover, they obtained levels of composite prosocial moral reasoning comparable to results highlighted by literature. 
In relation to hypotheses linked to sex differences, results confirmed that girls were more inclined than boys to help others in emotionally evocative, emergency or crisis situations $\left(\mathrm{H}_{1 \mathrm{~b}}\right)$ and obtained higher levels than boys in composite PMR $\left(\mathrm{H}_{1 \mathrm{c}}\right)$ while boys were more inclined than girls to adopt prosocial behaviors in public situations $\left(H 1_{d}\right)$. The hypothesis that girls scored higher than boys in anonymous prosocial behaviors $\left(\mathrm{H}_{1 \mathrm{a}}\right)$ wasn't confirmed by our results.

Differences for age confirmed that young adults scored higher than adolescents in anonymous prosocial behaviors $\left(\mathrm{H}_{2 \mathrm{a}}\right)$ and in composite PMR $\left(\mathrm{H}_{2 \mathrm{c}}\right)$ and that adolescents scored higher than young adults in public prosocial behaviors $\left(\mathrm{H}_{2 \mathrm{~d}}\right)$. The $\mathrm{H}_{2 \mathrm{~b}}$ was not confirmed.

Results partially confirmed our hypotheses in reference with relationships between the two constructs:

1. helping behaviors in emotionally critical and dire situations were positively related to composite and internalized PMR and negatively related to approval oriented PMR (H3). No relationships were found for hedonistic, stereotypical, and needs oriented PMR;

2. public prosocial behaviors were related positively to needs oriented and approval oriented PMR and negatively to composite and internalized PMR (H4). No relationships were found for hedonistic and stereotypical PMR;

3. anonymous prosocial behaviors, only for girls, were related positively to composite and internalized PMR and negatively related to needs oriented PMR (H5). No relationships were found for hedonistic and approval oriented prosocial reasoning while, in opposition to our hypothesis, anonymous prosocial behaviors were negatively related to stereotypical PMR.

Results of the present study confirmed, also in Italian context, outcomes emerged in other studies, with the exception of researches carried out with Chinese [24] and Iranian samples [27], in relation to sex and age differences both on prosocial behavior $([4,8,9])$ and PMR $([16,18,19,20,21,23,25])$. Similarly, results on relationships between prosocial behavior and moral reasoning confirmed the trend highlighted in the afore mentioned studies $([4,8,26])$.

Future studies could deepen the relationships among prosocial behavior and moral reasoning and other psychological constructs such as moral disengagement, humor styles (as already verified by Falanga et al. [28] in a sample of middle adolescents) and value priorities (see Caprara et al., [29,30]) in order to improve our knowledge on these topics in Italian context and in other developmental ages.

\section{References}

[1] Padilla-Walker, L. M., \& Carlo, G. (Eds.). (2014). Prosocial Development: A multidimensional approach. New York: Oxford University Press.

[2] Caprara, G. V., \& Bonino S. (2006). Il comportamento prosociale. Aspetti individuali, familiari e sociali [Prosocial behavior. Individual, familiar, and social aspects]. Trento: Erikson.

[3] Harter, S. (1999). The construction of the self: A developmental perspective. New York: Guilford.

[4] Carlo, G., \& Randall, B.A. (2002). The development of a measure of prosocial behaviors for late adolescents, Journal of Youth and Adolescence, 31, 31-44.
[5] Eisenberg, N., \& Fabes, R. A. (1998). Prosocial development. In W. Damon (Series Ed.) and N. Eisenberg (Vol. Ed.), Handbook of child psychology: Vol. 3. Social, emotional, and personality development (5th ed., pp. 701-778). New York: Wiley.

[6] Green, B., Shirk, S., Hanze, D., \& Wanstrath, J. (1994). The Children's Global Assessment Scale in clinical practice: An empirical evaluation. Journal of American Academy of Child and Adolescent Psychiatry, 33, 1158-1164.

[7] Rydell, A. M., Hagekull, B., \& Bohlin, G. (1997). Measurement of two social competence aspects in middle childhood. Developmental Psychology, 33, 824-833.

[8] Carlo, G., Hausmann, A., Christiansen, S., \& Randall, B. A., (2003). Sociocognitive and Behavioral Correlates of a Measure of Prosocial Tendencies for Adolescents. Journal of Early Adolescence, 23, 107-134.

[9] De Caroli, M. E., \& Sagone, E. (2013). Self-efficacy and Prosocial Tendencies in Italian Adolescents. Procedia-Social and Behavioral Sciences, 92, 239-245.

[10] Eisenberg, N., \& Mussen, P. H. (1989). The roots of prosocial behavior in children. New York: Cambridge University Press.

[11] Eisenberg, N. (1979). Development of children's prosocial moral judgment. Developmental Psychology, 15, 128-137.

[12] Eisenberg-Berg, N. (1979). The development of children's prosocial moral judgment. Developmental Psychology, 15, 128137.

[13] Carlo, G., Eisenberg, N., Knight, G. P. (1992). An objective measure of adolescents' prosocial moral reasoning. Journal of Research on Adolescence, 2, 331-349.

[14] Eisenberg, N., Lennon, R., \& Roth, K. (1983). Prosocial development: A longitudinal study. Developmental Psychology, 19, 846-855.

[15] Eisenberg, N., Shell, R., Pasternack, J., Lennon, R., Beller, R., \& Mathy, R.M. (1987). Prosocial development in middle childhood: A longitudinal study. Developmental Psychology, 23, 712-718.

[16] Eisenberg, N., Cumberland, A., Guthrie, I. K., Murphy, B. C., Shepard, S.A. (2005). Age changes in prosocial responding and moral reasoning in adolescence and early adulthood. Journal of Research on Adolescence, 15, 235-260.

[17] Eisenberg., N., Guthrie, I K., Murphy, B. C., Shepard, S. A., Cumberland, A., \& Carlo, G. (1999). Consistency and development of prosocial dispositions: a longitudinal study. Child Development, 70, 1360-1372.

[18] Eisenberg, N., Guthrie, I., Cumberland, A., Murphy, B. C., Shepard, S. A., Zhou, Q., \& Carlo, G. (2002). Prosocial development in early adulthood: A longitudinal study. Journal of Personality and Social Psychology, 82, 993-1006.

[19] Eisenberg, N., Miller, P. A., Shell, R., McNalley, S., \& Shea, C. (1991). Prosocial development in adolescence: A longitudinal study. Developmental Psychology, 27, 849-857.

[20] Eisenberg, N., Hofer, C., Sulik, M. J., \& Liew, J. (2014). The development of prosocial moral reasoning and a prosocial orientation in young adulthood: concurrent and longitudinal correlates. Developmental Psychology, 50, 58-70.

[21] Carlo, G., Koller, S. H., Eisenberg, N., Da Silva, M. S., \& Frohlich, C. B. (1996). A cross-national study on the relations among prosocial moral reasoning, gender role orientations and prosocial behaviors. Developmental Psychology, 32, 231-240.

[22] Eisenberg, N., Zhou, Q., \& Koller, S. (2001). Brazilian adolescents' prosocial moral judgment and behavior: Relations to sympathy, perspective taking, gender-role orientation, and demographic characteristics. Child Development, 72, 518-534.

[23] Falanga, R. (2010). Il ragionamento prosociale in adolescenza. Uno studio esplorativo nel contesto siciliano [Prosocial reasoning in adolescence. An esplorative study in Sicilian context]. In Annali della Facoltà di Scienze della Formazione-Università di Catania Vol. 7 (pp. 151-165). Catania: Università degli studi.

[24] Lai, F. H. Y., Siu, A. M. H., Chan, C. C. H., \& Shek, D. T. L. (2012). Measurement of prosocial reasoning among Chinese adolescents. The Scientific World Journal.

[25] Azimpour, A., Neasi, A., Shehni-Yailagh, M., Arshadi, N., \& Beshilde, K. (2013). Assessment prosocial moral reasoning on Iranian: Evaluation the measurement model and validation the measure of prosocial moral reasoning on Iranian university students. Journal of Life Science and Biomedicine, 3, 1, 10-15.

[26] Hardy, S. A., \& Carlo, G. (2005). Religiosity and prosocial behaviours in adolescence: the mediating role of prosocial values. Journal of Moral Education, 34, 2, 231-249. 
[27] Azimpour A., Neasi A., Shehni-Yailagh M., \& Arshadi N. (2012) Validation of "Prosocial Tendencies Measure" in Iranian university students. Journal of Life Science and Biomedicine, 2, 34-42.

[28] Falanga, R., De Caroli, M. E., \& Sagone, E. (2014). Humor Styles, Self-efficacy and Prosocial Tendencies in Middle Adolescents, Procedia-Social and Behavioral Sciences, 127, 214-218.
[29] Caprara, G. V., \& Steca, P. (2005). Self-efficacy beliefs as determinants of prosocial behavior conducive to life satisfaction across ages. Journal of Social and Clinical Psychology, 24, 191217.

[30] Caprara, G.V., Alessandri, G., \& Eisenberg, N. (2012). Prosociality: the contribution of traits, values, and self-efficacy beliefs. Journal of Personality and Social Psychology, 102, 12891303. 